\title{
Ducting and Biases of GPS Radio Occultation Bending Angle and Refractivity in the Moist Lower Troposphere
}

\author{
Xuelei Feng And Feiqin XIE \\ Department of Physical and Environmental Sciences, Texas A\&M University-Corpus Christi, Corpus Christi, Texas \\ CHI O. AO \\ Jet Propulsion Laboratory, California Institute of Technology, Pasadena, California \\ RICHARD A. ANTHES \\ COSMIC Program Office, University Corporation for Atmospheric Research, Boulder, Colorado
}

(Manuscript received 5 December 2019, in final form 15 April 2020)

\begin{abstract}
Radio occultation ( $\mathrm{RO}$ ) can provide high-vertical-resolution thermodynamic soundings of the planetary boundary layer (PBL). However, sharp moisture gradients and strong temperature inversion lead to large gradients in refractivity $N$ and often cause ducting. Ducting results in systematically negative RO $N$ biases resulting from a nonunique Abel inversion problem. Using 8 years (2006-13) of Constellation Observing System for Meteorology, Ionosphere and Climate (COSMIC) RO soundings and collocated European Centre for Medium-Range Weather Forecasts interim reanalysis (ERA-I) data, we confirm that the large lowertropospheric negative $N$ biases are mainly located in the subtropical eastern oceans and we quantify the contribution of ducting for the first time. The ducting-contributed $N$ biases in the northeast Pacific Ocean $\left(160^{\circ}-110^{\circ} \mathrm{W} ; 15^{\circ}-45^{\circ} \mathrm{N}\right)$ are isolated from other sources of $N$ biases using a two-step geometric-optics simulation. Negative bending angle biases in this region are also observed in COSMIC RO soundings. Both the negative refractivity and bending angle biases in COSMIC soundings mainly lie below $\sim 2 \mathrm{~km}$. Such bending angle biases introduce $N$ biases that are in addition to those caused by ducting. Following the increasing PBL height from the southern California coast westward to Hawaii, centers of maxima bending angles and $N$ biases tilt southwestward. In areas where ducting conditions prevail, ducting is the major cause of the RO $N$ biases. Ducting-induced $N$ biases with reference to ERA-I compose over $70 \%$ of the total negative $N$ biases near the southern California coast, where strongest ducting conditions prevail, and decrease southwestward to less than $20 \%$ near Hawaii.
\end{abstract}

\section{Introduction}

Since the proof-of-concept demonstration of the Global Positioning System (GPS)/Meteorology experiment in 1995-97 (Ware et al. 1996), many GPS radio occultation $(\mathrm{RO})$ satellite missions have been successfully deployed (e.g., Anthes et al. 2008; Anthes 2011). Radio occultation offers high-precision, highvertical-resolution, and all-weather global sounding capability, which complement passive infrared and microwave sounders, and contribute to global weather forecasting and atmospheric research. Numerous studies have demonstrated the high quality of RO data in

\footnotetext{
Corresponding author: Feiqin Xie, feiqin.xie@tamucc.edu
}

the upper troposphere and lower stratosphere from GPS/Meteorology (MET) (Rocken et al. 1997; Kursinski et al. 1997; Feng and Herman 1999; Tsuda et al. 2000) and CHAMP (Wickert et al. 2001). However, these earlier RO missions, which were equipped with phase-locked loop tracking receivers, encountered significant signal tracking challenges in the presence of large moisture variations in the lower troposphere. The complicated signal dynamics led to degraded RO signals and poorer data quality in the lower troposphere, such as systematic negative biases in bending angle and refractivity retrievals, along with low frequency of penetration into the lowest $1-2 \mathrm{~km}$ of the atmosphere (Ao et al. 2003; Beyerle et al. 2003; Sokolovskiy 2003; Beyerle et al. 2006). 
The implementation of open-loop tracking on the RO receivers allows high-quality RO signal tracking deep into the moist lower troposphere (Sokolovskiy et al. 2006; Ao et al. 2009). Over $80 \%$ of the retrieved profiles reach below $2 \mathrm{~km}$ altitude in the tropics, as compared with only $\sim 50 \%$ under closed-loop tracking (Ao et al. 2012). Nearly $85 \%-90 \%$ of RO soundings reach below $1 \mathrm{~km}$ over the much drier Arctic Ocean (Yu et al. 2018). In addition, geometric-optics (GO) $\mathrm{RO}$ retrievals frequently encounter multipath problems in the presence of lower-tropospheric moisture variations, which cause negative biases in the RO retrieved bending angle and refractivity profiles (Gorbunov and Gurvich 1998). The introduction of the radioholographic retrieval algorithms resolves the atmospheric multipath problems (Gorbunov 2002a,b; Sokolovskiy 2003; Jensen et al. 2003, 2004), and reduces RO biases in the moist lower troposphere. These techniques also overcome the limitation from Fresnel diffraction, and improve the vertical resolution up to $\sim 60 \mathrm{~m}$ (Gorbunov et al. 2004).

Since 2006, the six-satellite Constellation Observing System for Meteorology, Ionosphere and Climate (COSMIC), also known as the Formosa Satellite Mission 3 (FORMOSAT-3) in Taiwan, and the Global Navigation Satellite System (GNSS) Receiver for Atmospheric Sounding (GRAS) on board MetOp has produced over 3000 daily soundings globally (Anthes et al. 2008; Luntama et al. 2008). The RO soundings are operationally assimilated into the numerical weather prediction models at many weather forecast centers and have demonstrated positive impacts in the upper troposphere and lower stratosphere (Healy and Thépaut 2006; Cucurull and Derber 2008). RO observations have advanced the knowledge of various physical processes, including the troposphere-stratosphere exchange, gravity waves, planetary boundary layer (PBL), and hurricane/typhoon evolution (Anthes 2011; Bonafoni et al. 2019; Ho et al. 2019; and references therein). Numerous studies have demonstrated the values of RO soundings in detecting the PBL height (e.g., Sokolovskiy et al. 2006, 2007; Ao et al. 2008; Basha and Ratnam 2009; Guo et al. 2011; Ao et al. 2012; Xie et al. 2012). However, probing the PBL interior with RO remains challenging due to the existence of negative refractivity biases (hereinafter negative $N$ biases) inside the moist PBL (Xie et al. 2010). The systematic $N$ biases are especially pronounced in the lower troposphere over the subtropical eastern oceans (Xie et al. 2010, 2012), where ducting is frequently observed (e.g., von Engeln and Teixeira 2004; Lopez 2009).

In the presence of ducting, it has been demonstrated that significant negative $N$ biases result from the nonunique inversion problem in the standard Abel inversion used to derive the RO refractivity retrieval from bending angles (Sokolovskiy 2003; Ao et al. 2003; Xie et al. 2006; Ao 2007). Theoretical explanations of the ducting induced $N$ biases from the standard Abel inversion can be found in Xie (2006) and Xie et al. (2006). It is worth noting that under the local spherically symmetric atmosphere assumption, the presence of ducting does not introduce biases in the RO bending angle when RO signals are perfectly recorded (Sokolovskiy 2003).

Xie et al. (2010) found a major contribution of ducting to the RO $N$ biases in the lower troposphere. The large refractivity gradient associated with the ducting layer has a profound impact on the propagation of GPS radio signals and results in significant changes in both the phase and signal-to-noise-ratio (SNR) of the RO signals (Sokolovskiy 2003), which may lead to bending angle errors and additional refractivity errors. The impact of signal tracking errors on the RO refractivity retrieval has been demonstrated in RO measurements from airborne platforms (Wang et al. 2016). To reduce refractivity biases due to ducting, additional information is needed. A recent study showed that collocated precipitable water vapor retrieved from microwave radiometer measurements can be used in combination with the RO bending angle profiles to retrieve unbiased refractivity profiles in the presence of ducting (Wang et al. 2017).

In this paper, we analyze COSMIC RO bending angle and refractivity errors in reference to the European Centre for Medium-Range Weather Forecasts (ECMWF) interim reanalysis (ERA-Interim, hereinafter ERA-I) and in situ radiosonde soundings with the focus on the northeast Pacific Ocean, where the Marine Atmospheric Radiation Measurement (ARM) GCSS Pacific CrossSection Intercomparison (GPCI) Investigation of Clouds (MAGIC) experiment was carried out (Zhou et al. 2015). The $N$ biases solely due to the standard Abel inversion problem in the presence of ducting in the ERA-I data are quantified, and the remaining $N$ biases due to other factors are also estimated. Section 2 presents data and methodology used for this study. The global distributions of ducting frequency from the reanalysis, and the PBL refractivity and $N$ biases from COSMIC RO soundings are described in section 3. Section 4 details the mean bending angle and $N$ biases over the northeast Pacific Ocean, and further estimates the fraction of $N$ biases resulting from the standard Abel retrieval in the presence of ducting in the ERA-I data. Section 5 summarizes the results and conclusions.

\section{Data and method}

\section{a. Data description}

The COSMIC level-2 refractivity and bending angle data are obtained from UCAR (https://cdaac-www. cosmic.ucar.edu/). The retrieval procedures are described 
in Kuo et al. (2004). The refractivity is reported as a function of geometric height above mean sea level (MSL), and the bending angle is reported as a function of impact parameter, which is the product of refractive index and radius at the tangent point. Although RO soundings could theoretically achieve $\sim 60-\mathrm{m}$ vertical resolution (Gorbunov et al. 2004; Zeng et al. 2019), the resolution of $\mathrm{RO}$ bending angle and refractivity profiles in the lower troposphere is limited by a $200-\mathrm{m}$ filter applied in the standard retrieval (Ho et al. 2009) to reduce measurement noise.

Six-hourly air temperature $T$, pressure $P$, and specific humidity $q$ from ERA-I are used. The ERA-I archive is a global atmospheric reanalysis from 1979 (Dee et al. 2011). It has a spectral resolution of T255, with a horizontal grid of $\sim 0.75^{\circ}$ latitude $\times 0.75^{\circ}$ longitude $(\sim 80 \mathrm{~km}$ near the equator), on 60 vertical levels from the surface up to the $0.1-\mathrm{hPa}$ pressure level. There are about 14 unevenly spaced layers below $2 \mathrm{~km}(\sim 800 \mathrm{hPa})$, with denser sampling near the surface. The vertical resolution is $\sim 200 \mathrm{~m}$ between 900 and $800 \mathrm{hPa}$, decreasing to $\sim 30 \mathrm{~m}$ near the surface. ERA-I assimilates COSMIC RO bending angles (Healy 2008), but it does not assimilate bending angles below the ducting layer, which generally occurs near the PBL top (Poli et al. 2010). Because ducting occurs frequently over the subtropical eastern oceans, including the northeast Pacific Ocean (von Engeln and Teixeira 2004; Lopez 2009), the RO and the reanalysis data can be considered to be mostly independent inside the PBL in these regions. For each COSMIC profile, the closest collocated ERA-I profile within $3 \mathrm{~h}$ in time and less than $\sim 40 \mathrm{~km}$ in space (e.g., within $0.375^{\circ}$, or half-size of an ERA-I grid) over the northeast Pacific Ocean $\left(160^{\circ}-110^{\circ} \mathrm{W} ; 15^{\circ}-45^{\circ} \mathrm{N}\right)$ was identified. A total of 152249 collocated pairs over this region were analyzed.

Furthermore, shipborne radiosonde measurements from the MAGIC experiment are used. The refractivity profiles can be calculated from the radiosonde temperature $T$, pressure $P$, and relative humidity $(\mathrm{RH})$ measurements. The MAGIC field campaign implemented the U.S. Department of Energy Atmospheric Radiation Measurement Program Mobile Facility 2 (AMF2) on the commercial cargo container ship Horizon Spirit (Kalmus et al. 2015). The ship traveled back and forth along a near-straight line between Los Angeles, California, and Honolulu, Hawaii, from 26 September 2012 to 2 October 2013 (Zheng and Rosenfeld 2015). Radiosondes were launched every $6 \mathrm{~h}$ initially but were launched every $3 \mathrm{~h}$ after July 2013 (Zhou et al. 2015). A total of 583 radiosonde soundings were obtained. For each MAGIC radiosonde profile, the closest collocated COSMIC $\mathrm{RO}$ profile (if available) is identified within $3 \mathrm{~h}$ and $\sim 3^{\circ}$. The larger distance collocation criterion for radiosonde allows more collocated profiles (177 pairs) to be found.

\section{b. Bending angle and refractivity simulation in the presence of ducting}

In the neutral atmosphere, the refractivity $N$, a dimensionless quantity defined as $N=(n-1) \times 10^{6}$, where $n$ is the refractive index, is related to the atmospheric pressure $P$ (in hectopascals), temperature $T$ (in kelvins), and water vapor partial pressure $P_{w}$ (in hectopascals) through (Smith and Weintraub 1953)

$$
N=77.6 \frac{P}{T}+3.73 \times 10^{5} \frac{P_{w}}{T^{2}} .
$$

Under the assumption of a local spherically symmetric atmosphere, a ray satisfies Bouguer's law; that is, the impact parameter $[a=r n(r) \sin \varphi]$ is a constant for a given ray in the GO approximation, where $r$ is the distance from the center of curvature and $\varphi$ is the angle between the ray path and the radial direction (Born and Wolf 1964). The total refractive bending angle $\alpha$, as a function of $r_{t}$ (i.e., the radius of the ray at the tangent point), is given by Fjeldbo et al. (1971) in (2), which can be further simplified to (3) given that $a(r)$ is a monotonic function and using the substitution $x=n(r) r$ :

$$
\begin{aligned}
\alpha(a) & =-2 a \int_{r_{t}}^{\infty} \frac{1}{n} \frac{d n}{d r} \frac{d r}{\sqrt{(n r)^{2}-a^{2}}} \\
& =-2 a \int_{a}^{\infty} \frac{1}{n} \frac{d n}{d x} \frac{d x}{\sqrt{x^{2}-a^{2}}} .
\end{aligned}
$$

In the presence of a ducting layer, the impact parameter $a$ is no longer a monotonic function of $r$ inside and right below the ducting layer (e.g., Xie et al. 2006), and (2) instead of (3) is needed for calculating $\alpha$. A detailed description of the special treatment of solving (2) in the presence of ducting layer can be found in Xie et al. (2006). Given a bending angle profile, the refractive index $n(r)$, is then solved by inverting (3) through the Abel inversion (Fjeldbo et al. 1971)

$$
n(r)=\exp \left[\frac{1}{\pi} \int_{a}^{\infty} \frac{\alpha(x) d x}{\sqrt{x^{2}-a^{2}}}\right]
$$

Using the MAGIC radiosonde and ERA-I refractivity profiles calculated from (1), a simple two-step end-to-end GO simulation can be conducted. First, a forward operator is used to simulate the RO bending angle measurement by integrating an input refractivity profile [(2) or (3)]. Second, an inverse operator is used to simulate the RO refractivity retrieval process 

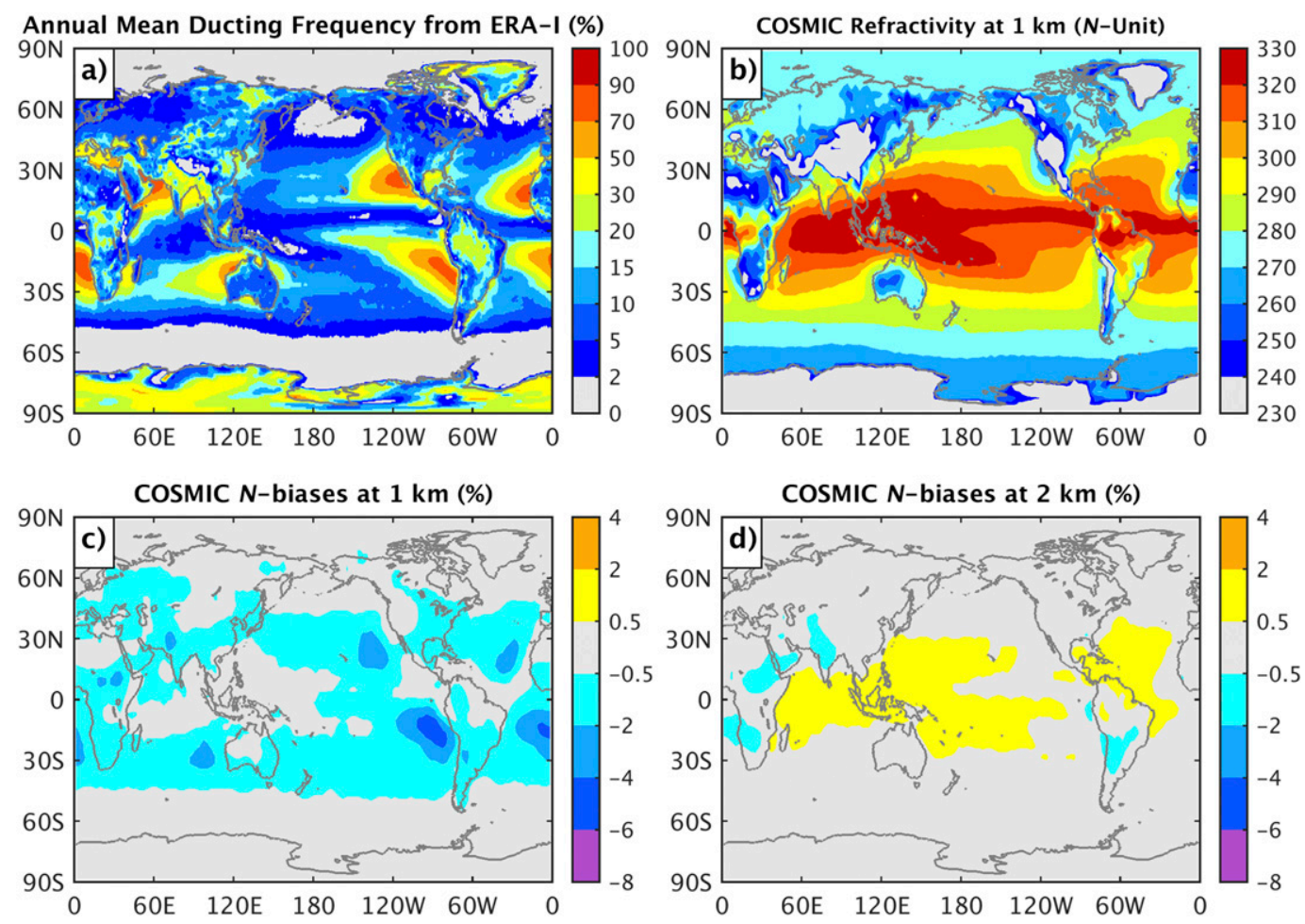

FIG. 1. (a) Annual mean (2006-13) ducting frequency from ERA-I, (b) annual mean COSMIC refractivity $N$ at $1 \mathrm{~km}$, and fractional COSMIC refractivity biases with respect to collocated ERA-I at (c) 1- and (d) 2-km level. The COSMIC fractional $N$ bias is defined as $\left\langle\left(N_{\text {COSMIC }}-N_{\text {ERAI }}\right) / N_{\text {ERAI }}\right\rangle \times 100 \%$, where angle brackets denote the sample mean. Ducting frequency in (a) is defined as the percentage of soundings with ducting at any level to the total refractivity profiles in ERA-I. The values in (b)-(d) are displayed at altitudes above the surface, which were converted from the height above mean sea level by subtracting high-resolution terrain data.

by integrating the simulated bending angle profile through the standard Abel integration. The two GO operators that are specifically built for simulating ducting cases are described in Xie (2006) and Xie et al. (2006).

The MAGIC and ERA-I refractivity profiles are normally up to $\sim 30$ and $\sim 50 \mathrm{~km}$, respectively. In the bending angle simulations, this existing segment of each refractivity profile is interpolated to a $10-\mathrm{m}$ computational grid, while above the top level, all refractivity profiles are extrapolated exponentially. In the absence of ducting, the Abel-retrieved refractivity profile will be identical to the input refractivity profile. However, in the presence of a duct, the Abel-retrieved refractivity profile becomes negatively biased inside the PBL. The percentage of ducting-induced $N$ biases can therefore be isolated and quantified as $\left(N_{-}\right.$retrieval $\left.-N_{\text {input }}\right) / N_{-}$input $\times 100 \%$.

\section{Ducting climatology and the $N$ biases in $\mathbf{R O}$ soundings}

An atmospheric duct is a horizontal layer in the atmosphere in which the vertical refractivity gradient is less than a critical value of $-157 \mathrm{~N}$-units per kilometer such that radio signals are guided or ducted to follow Earth's curvature (Thomas 2006). The sharp refractivity gradient is generally caused by a coexisting sharp temperature inversion and negative moisture gradient across the top of the PBL. Here we analyzed ERA-I refractivity profiles from 2006 to 2013 . The refractivity gradient profile is calculated at the model levels. A profile with ducting is identified when the minimum refractivity gradient is less than the critical value of $-157 N$-units per kilometer.

The 8-yr mean annual ducting occurrence frequency is shown in Fig. 1a. This annual mean ducting frequency pattern is highly consistent with the results in Lopez (2009). The regions with high ducting frequency are clustered over the subtropical eastern oceans, where strong subsidence in the free troposphere along with the cool sea surface temperature results in strong temperature inversion. The sharp moisture gradient beneath the temperature inversion leads to a large refractivity gradient, and often causes ducting across the PBL top (Xie et al. 2010). Six centers of high ducting frequency occur over the subtropical oceans off the west coast of 

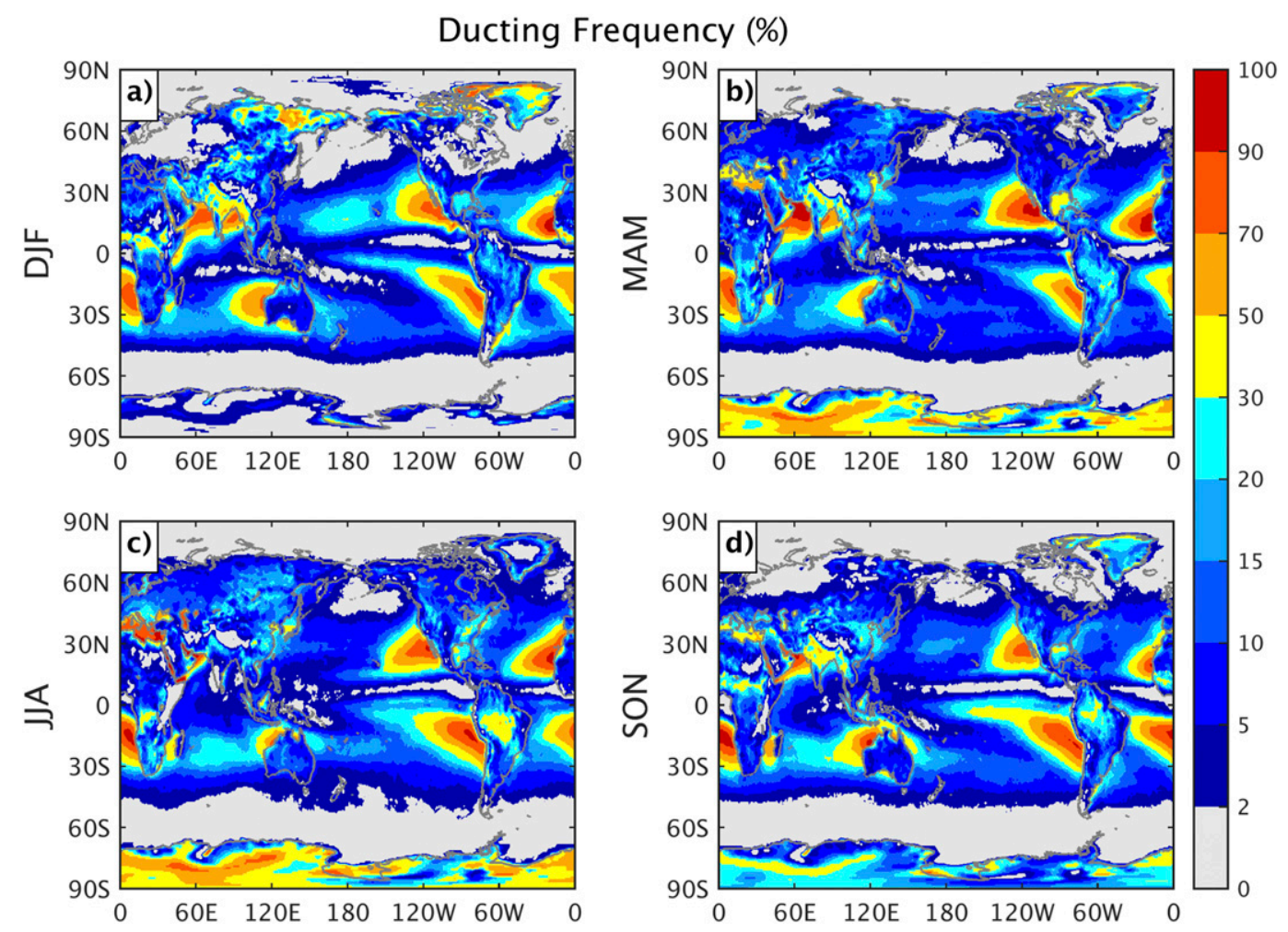

FIG. 2. Seasonal-mean ducting frequency (\%) from ERA-I in (a) DJF, (b) MAM, (c) JJA, and (d) SON. The values pertain to any layer in ERA-I with ducting.

continents, including North/South America, North/South Africa, and India/Australia, with the maximum ducting frequency exceeding 90\%. Over the polar regions, including the Arctic, and the Antarctic Circumpolar Current areas, ducting is rarely observed.

The annual mean COSMIC refractivity at $1 \mathrm{~km}$ above surface is exhibited in Fig. 1b, which is similar to that of ERA-I (not shown). Note this mean COSMIC refractivity panel (Fig. 1b), as well as $N$-bias-related figures in this section (Figs. 1c,d, 2, and 4), is binned and displayed at the $3^{\circ}$ latitude $\times 3^{\circ}$ longitude grids. The refractivity maxima are centered on the tropical deep convective regions. Besides the polar regions, minimum refractivity values are also seen over high topography areas, such as Tibet Plateau, Andes, west coast of the United States, and Greenland due to the relatively lower surface pressure, and the drier and cooler near-surface conditions. Minimum refractivity values also exist in the subtropical and midlatitude deserts, such as the Sahara and the Kalahari in Africa, Atacama and Patagonian in South America, western Australia, and the Gobi, Taklamakan, and Arabian deserts.

By differencing each COSMIC refractivity profile with its collocated ERA-I profile, the fractional RO refractivity error profile in reference to ERA-I can be estimated. Note the refractivity profiles from both COSMIC and ERA-I are interpolated to a $100-\mathrm{m}$ vertical grid before the differencing. The 8-yr annual mean $N$-bias maps at 1 and $2 \mathrm{~km}$ above the surface are shown in Figs. 1c and 1d. Similar to Xie et al. (2012), large lower-tropospheric $N$ biases are confined over the low latitudes $\left(30^{\circ} \mathrm{S}-30^{\circ} \mathrm{N}\right.$, excluding the ITCZ/SPCZ), but are absent in higher latitudes. At the $1-\mathrm{km}$ level (Fig. 1c), the $N$ biases are mostly clustered over the subtropical eastern oceans, which are characterized with high ducting frequency as seen in Fig. 1a. Over land there are also large $N$ biases over the complex topography regions, such as the Andes, Himalaya Mountains and central Africa. The maximum negative $N$ biases over the oceans can reach $\sim 6 \%$. It is important to note that these estimated $N$ biases could be affected by biases in the ERA-I reanalysis as well as the RO retrievals. For example, Ho et al. (2015) found a low-bias in the ERA-I PBL height of about $300 \mathrm{~m}$ off the coast of South America, a region with frequent ducting. However, a comparison of collocated refractivity profiles between ERA-I and MAGIC radiosondes shows very small ERA-I $N$ biases (not shown). In the rest of this study, we assume that the ERA-I reanalysis is accurate enough to represent the refractivity of the real atmosphere. 
$\mathrm{N}$-biases at $1 \mathrm{~km}(\%)$
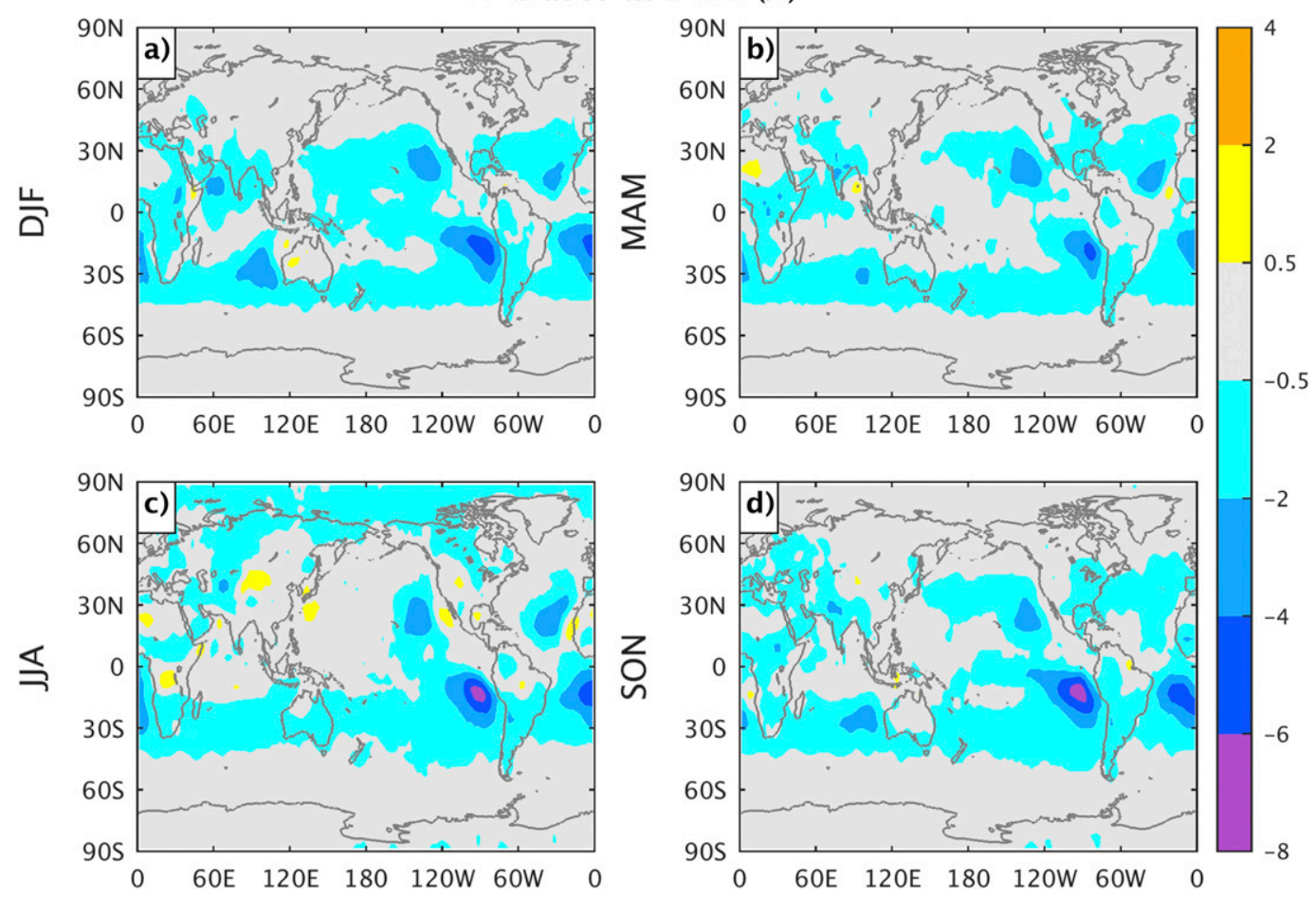

FIG. 3. Seasonal mean fractional refractivity difference ( $N$ biases) between COSMIC RO and collocated ERA-I at $1 \mathrm{~km}$ above the surface in (a) DJF, (b) MAM, (c) JJA, and (d) SON.

As pointed out by Xie et al. (2010), the highly consistent pattern between the $N$ biases at $1 \mathrm{~km}$ and ducting frequency over the subtropical oceans strongly supports the importance of ducting in producing the negative $N$ biases in the lowermost troposphere. The $N$ biases over land, however, do not appear to be related to ducting, and will require further investigation. Interestingly, the high frequency of ducting in the Antarctic region is also not reflected in the $N$ biases (Fig. 1c). That is likely due to the limited GPS RO sounding penetration and vertical resolution $(\sim 200 \mathrm{~m})$, which might not be able to identify the very shallow near-surface ducting layer over polar regions (Yu et al. 2018).

The negative $N$ biases at $1 \mathrm{~km}$ (Fig. 1c) become negligible or positive at the $2 \mathrm{~km}$ level (Fig. 1d), except over several small land regions where negative biases remain. These positive $N$ biases are primarily distributed in the tropical oceans including the tropical Indian Ocean, western Pacific, central Pacific off the equator, and western Atlantic Ocean. They have also been reported by several other studies (Ao et al. 2003; Beyerle et al. 2006; Sokolovskiy et al. 2010; Xie et al. 2010). Sokolovskiy et al. (2010) showed that random noise associated with small-scale variations of lower-tropospheric water vapor coupled with a decrease of the truncation height of the RO signal in the retrieval could cause a positive bias because of the asymmetry of the local spectrum of noise of the RO signal. Because the positive $N$ biases are not the emphasis of this study, we focus our study on the negative biases in the lower level.

The seasonal variation of the ducting frequency derived from the ERA-I reanalysis is evident in Fig. 2, which is consistent with the ECMWF operational analysis (Lopez 2009). The ducting events occur more often over ocean than over land, but the seasonality over land is stronger than that over ocean. Oceanic ducting prevails in the subtropics, with the maximum frequency clustering over the eastern oceans offshore of the western continents. The high-frequency region expands a little westward over the oceans in boreal autumn [September-November (SON); Fig. 2d] and winter [December-February (DJF); Fig. 2a] relative to spring [March-May (MAM); Fig. 2b] and summer [JuneAugust (JJA); Fig. 2c]. The north Indian Ocean has its highest frequency in MAM and the lowest in JJA, while the Mediterranean Sea reaches the maximum in JJA. Over land, high frequencies of ducting center around the Amazon in JJA and SON, over Antarctica in MAM and JJA, and over Russia and Greenland in DJF.

The seasonal mean COSMIC fractional $N$ biases in comparison to the ERA-I at $1 \mathrm{~km}$ above the surface is shown in Fig. 3. The $N$-bias distributions in the DJF and 

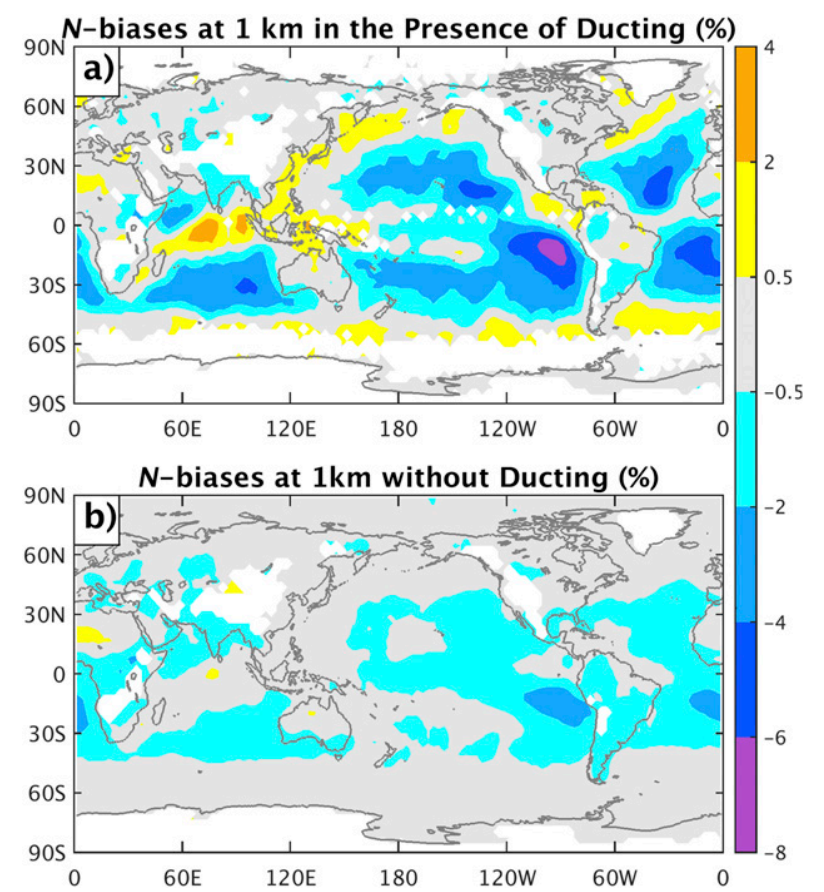

FIG. 4. COSMIC $N$ bias $\left\langle\left(N_{\text {COSMIC }}-N_{\text {ERAI }}\right) / N_{\text {ERAI }}\right\rangle \times 100 \%$ at $1 \mathrm{~km}$ above surface (a) in the presence of ducting and (b) in the absence of ducting as indicated by the collocated ERA-I profiles.

JJA are qualitatively consistent with the corresponding panels in Fig. 1 of Xie et al. (2010). The large biases are confined to the subtropical eastern oceans in MAM (Fig. 3b) and JJA (Fig. 3c), and extend far westward, almost covering the entire subtropical oceans in DJF (Fig. 3a) and SON (Fig. 3d). Moreover, significant negative $N$ biases only emerge over the Arctic in JJA. Over land, $N$ biases in central Africa areas are present in all seasons, albeit with seasonal variations in magnitude.

The systematic negative $N$ bias in COSMIC soundings due to the presence of ducting has been demonstrated in both observational and simulation studies (Sokolovskiy 2003; Xie et al. 2006; Ao 2007; Xie et al. 2010). However, a full quantitative assessment of the $N$ biases attributable to ducting and other factors has not been done. Figure $1 \mathrm{c}$ shows the total COSMIC RO $N$ biases in comparison with the collocated ERA-I. In the rest of this section, the COSMIC RO profiles are separated into two groups: the first group consists of RO profiles for which the collocated ERA-I refractivity profiles show the presence of ducting, and the second group consists of RO profiles for which ducting is not present in collocated ERA-I profiles.

The annual mean COSMIC RO $N$ biases in the presence of ducting (in ERA-I) at $1 \mathrm{~km}$ above the surface are displayed in Fig. 4a. The overall distribution of $N$ bias is consistent with the total $N$ bias shown in Fig. 1c, but with much larger magnitudes. Systematic negative $N$ biases also exist in the nonducting conditions (Fig. 4b), with similar pattern, but weaker in magnitude than those with ducting (Fig. 4a). The fractional negative $N$ bias under ducting conditions (Fig. 4a) can reach about $10 \%$ in magnitude, while the maximum in the nonducting case (Fig. 4b) is only about $3 \%$. The existence of significant $N$ biases in the nonducting situations suggests that factors other than ducting contribute to the negative biases. Additional evidence for $N$ biases from nonducting factors will be demonstrated with bending angle errors in section 4. Underestimation of ducting frequency in the ERA-I analysis could be another reason, as the relatively coarse vertical resolution of ERA-I might fail to resolve strong vertical temperature and water vapor gradients in the real atmosphere.

\section{Retrieval errors of COSMIC soundings over the subtropical northeast Pacific}

In this section we evaluate the refractivity and bending angle biases of COSMIC RO soundings against the collocated ERA-I reanalysis over the subtropical northeast Pacific, where the MAGIC field campaign was carried out. MAGIC radiosonde profiles are also used to confirm the existence of bending angle biases.

\section{a. COSMIC bending angle biases relative to MAGIC and ERA-I}

The $N$ biases in RO can be introduced by bending angle errors. As described in section 2, the simulated bending angles of the reference data (e.g., ERA-I or radiosonde) are computed from refractivity. The COSMIC RO bending angle errors can be estimated by comparing the collocated RO bending angles with the simulated reference bending angles.

We found a total of 177 collocated COSMIC and MAGIC radiosonde pairs. For consistency, the COSMIC and collocated ERA-I profiles over a quadrangle area $\left[\left(158^{\circ} \mathrm{W}, 21^{\circ} \mathrm{N}\right),\left(158^{\circ} \mathrm{W}, 23^{\circ} \mathrm{N}\right),\left(118^{\circ} \mathrm{W}, 35.5^{\circ} \mathrm{N}\right)\right.$, and $\left.\left(118^{\circ} \mathrm{W}, 33.5^{\circ} \mathrm{N}\right)\right]$ (outlined in Fig. 6, below, with red lines), roughly coinciding with the MAGIC ship tracks during the campaign period (26 September 2012-2 October 2013), were identified. We also found a total of 911 COSMIC and collocated ERA-I profiles within the quadrangle area.

The mean COSMIC bending angle profiles along with the collocated MAGIC and ERA-I simulated bending angles are shown in Figs. 5a and 5b. The highresolution input radiosonde refractivity profiles can result in significant finescale noise in the simulated MAGIC bending angles. Therefore, the MAGIC refractivity profiles were smoothed with a $100-\mathrm{m}$ moving average before calculating the bending angles. 

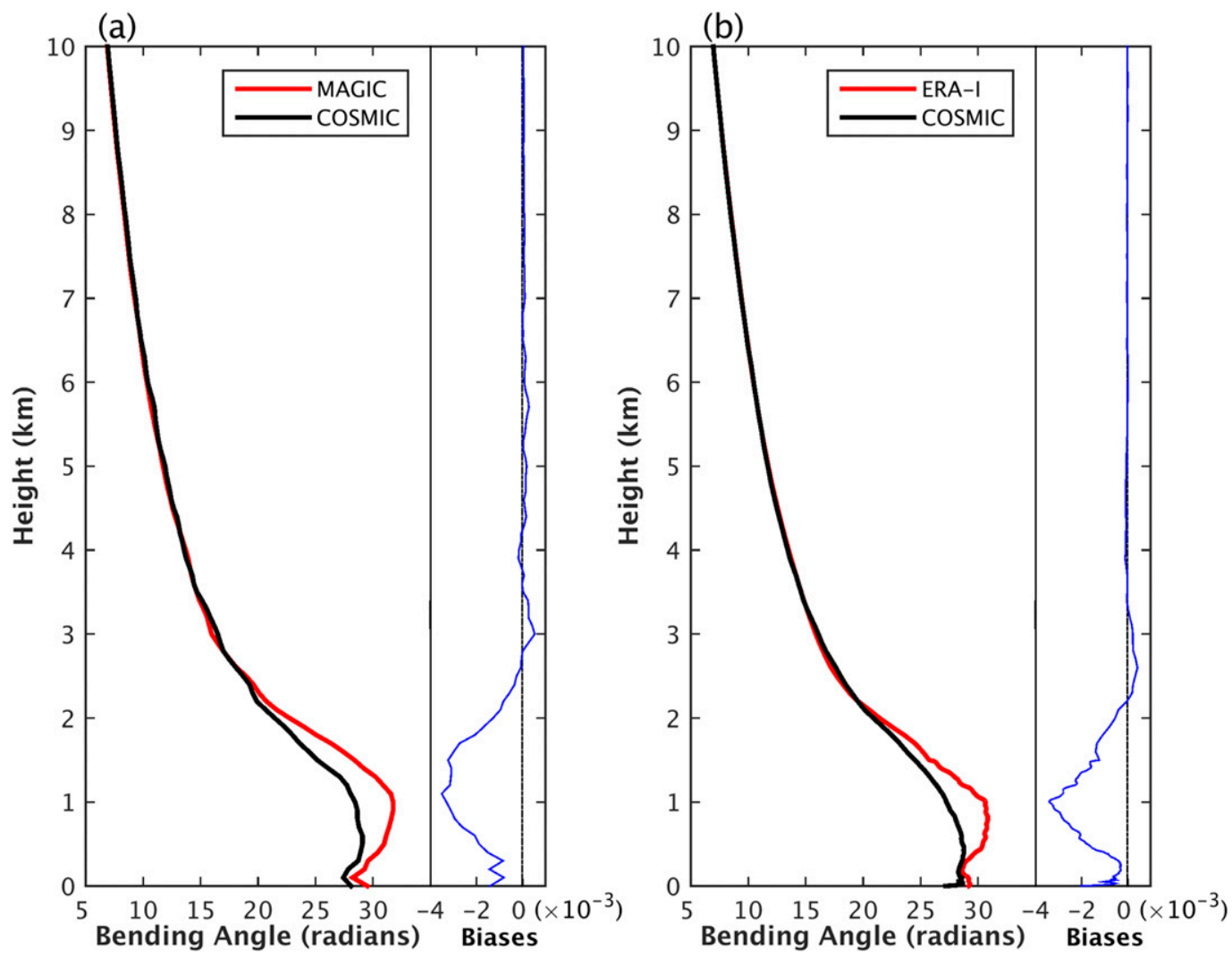

FIG. 5. Profiles of mean bending angle as a function of geometric height above mean sea level for (a) collocated COSMIC (black) and MAGIC radiosonde (red) (within $3 \mathrm{~h}$ and $3^{\circ}$ ) and (b) collocated COSMIC (black) and ERA-I (red) (within $3 \mathrm{~h}$ and $0.375^{\circ}$ ) roughly coinciding with the MAGIC ship tracks. The COSMIC bending angle bias profiles are displayed in the right side of the corresponding panels with blue lines.

To remove high-frequency noise, the simulated bending angle profiles are further vertically smoothed by a moving average of $50 \mathrm{~m}$.

In Fig. 5, negative COSMIC bending angle biases occur below $2 \mathrm{~km}$, while the biases above $2 \mathrm{~km}$ are negligible. The peak bending angle bias, as large as $\sim 10 \%$, occurs at $\sim 1 \mathrm{~km}$, where the maximum COSMIC bending angle reaches $\sim 0.028 \mathrm{rad}$, and the maximum ERA-I and MAGIC values reach $\sim 0.032 \mathrm{rad}$. The altitude of the peak bending angle in COSMIC is several hundred meters lower than those in the MAGIC and ERA-I profiles.

\section{b. COSMIC biases over the subtropical northeast Pacific}

For section $4 \mathrm{~b}$ we expand the study region beyond the MAGIC transect to the northeast Pacific from southern California to Hawaii $\left(160^{\circ}-110^{\circ} \mathrm{W} ; 15^{\circ}-45^{\circ} \mathrm{N}\right)$ and compare COSMIC RO soundings and the ERA-I profiles over the period of 21 April 2006-31 December 2013. The collocated data are binned into $2^{\circ}$ latitude $\times 2^{\circ}$ longitude grids in this section.
Systematically negative COSMIC bending angle biases with reference to ERA-I bending angles (Fig. 6) are shown at all four altitudes (0.5, 1.0, 1.5 and $1.8 \mathrm{~km} \mathrm{MSL)}$. At $0.5 \mathrm{~km}$, the large bending angle biases are confined to the ocean off the west coast of southern California. With increasing altitude, the bias center moves southwestward toward Hawaii, but covers less area. The peak bending angle bias, with the magnitude of $\sim-0.008 \mathrm{rad}$, occurs at $1 \mathrm{~km}$. From the MAGIC reference data, the PBL height increases from around $0.8 \mathrm{~km}$ near the California coast to $\sim 1.8 \mathrm{~km}$ near Hawaii. Thus the location of the maximum bending angle biases at each altitude follows the location of peak bending angle and the PBL height.

Figure 7 shows the fractional COSMIC $N$ biases with respect to ERA-I at four altitudes. This $N$-bias pattern qualitatively resembles the bending angle bias pattern (Fig. 6). The widespread negative $N$-bias center also gradually shifts from the ocean off the west coast of southern California at $0.5 \mathrm{~km}$ southwestward to Hawaii at higher levels.

Next we quantify the fraction of the $N$ biases caused by ducting based on the ERA-I data using the end-to-end 


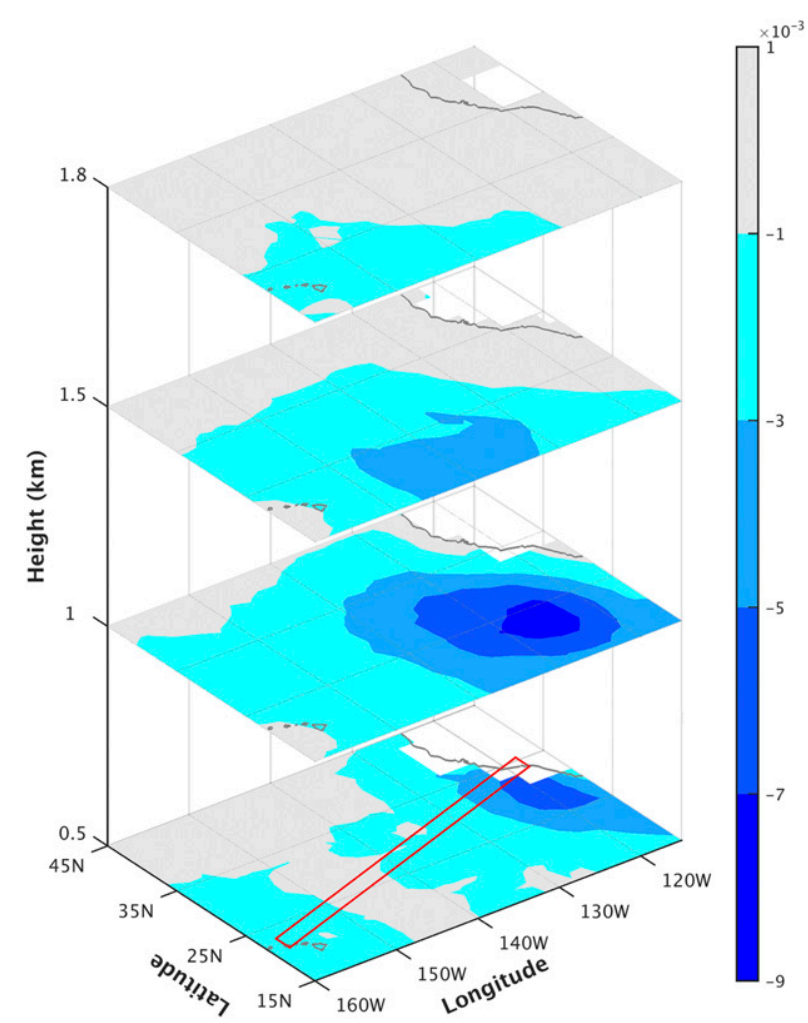

FIG. 6. COSMIC RO bending angle biases with respect to the ERA-I $\left\langle\left(\alpha_{\text {COSMIC }}-\alpha_{\text {ERAI }}\right)\right\rangle$ (rad) at $0.5,1.0,1.5$, and $1.8 \mathrm{~km}$ MSL. Red lines outline the area where the bending angle profiles of COSMIC and ERA-I are collocated for Fig. 5b. This area roughly coincides with the MAGIC ship tracks. Values on the color bar are times $10^{-3}$.

GO simulation described in section 2 . The bending angle profiles are first simulated given the input refractivity field from ERA-I ( $\left.N_{\text {ERAI }}\right)$, and then the simulated RO refractivity ( $\left.N_{\text {ERAI-simulated }}\right)$ are derived. In the presence of a ducting layer in ERA-I, the simulated refractivity retrieval will be negatively biased to the $N_{\text {ERAI }}$, and the simulated $N$ biases represent the ducting-caused $N$ biases. Figure 8 shows the fractional $N$ biases in the ERA-I caused by ducting $\left\langle\left(N_{\text {ERAI-simulated }}-N_{\text {ERAI }}\right) / N_{\text {ERAI }}\right\rangle \times$ $100 \%$. In comparison with the total COSMIC $N$ biases (Fig. 7), the ducting-induced $N$ biases share very similar pattern but with reduced magnitude.

The difference between the total and the ductinginduced $N$ biases, that is, the residual $N$ biases, is shown in Fig. 9. In addition to those biases associated with ducting, negative biases in bending angles and refractivity may also be caused by errors associated with low SNR in the complex moist lower troposphere (Sokolovskiy 2003; Beyerle et al. 2003; Kuo et al. 2004). Complicated refractivity structures in the lower troposphere result in rays (subsignals) with large bending angles and low amplitudes. These subsignals

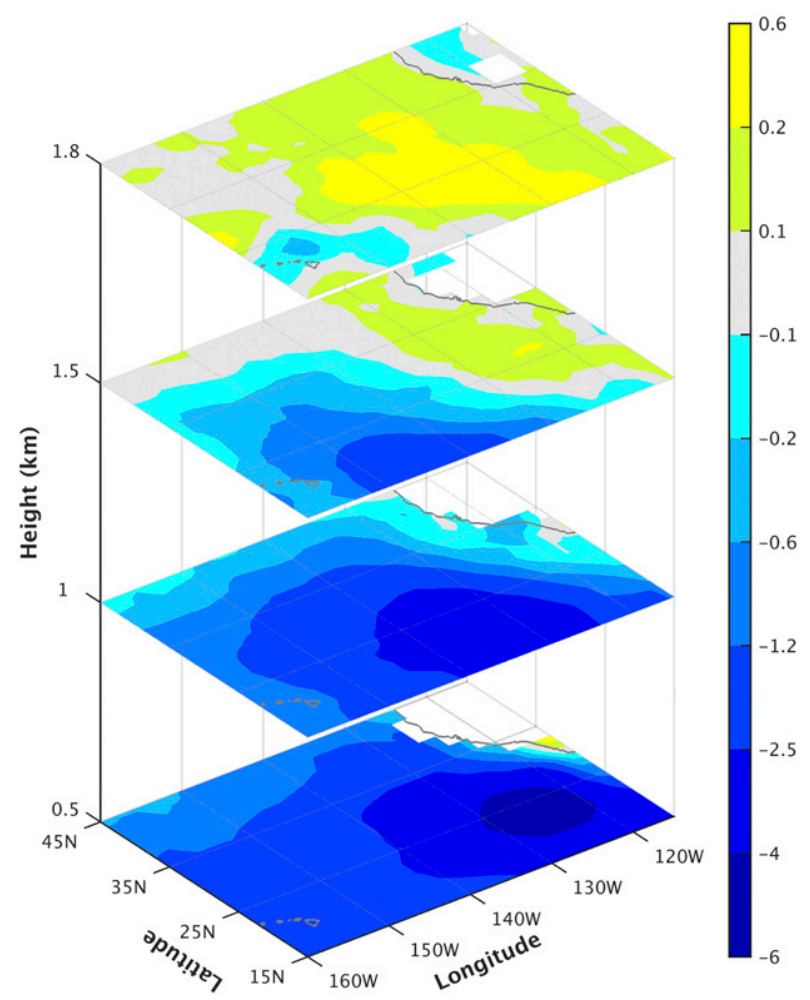

FIG. 7. COSMIC RO $N$ bias $\left\langle\left(N_{\text {COSMIC }}-N_{\text {ERAI }}\right) / \mathrm{N}_{\text {ERAI }}\right\rangle \times 100 \%$ with respect to ERA-I at $0.5,1.0,1.5$, and $1.8 \mathrm{~km}$ MSL.

cannot be resolved against the background noise and the RO signal must be truncated, preferentially removing subsignals with large bending angles from the inversion and resulting in a negative bias in bending angles and refractivity (Sokolovskiy et al. 2010). The underestimation of bending angles due to these effects has also been observed in airborne RO measurements (Wang et al. 2016).

Another potential source of negative bias is related to the propagation of radio waves in a medium with random refractivity irregularities. This nonlinear effect can be explained by Fermat's principle that a ray always takes the trajectory with the least time (and the minimum phase path), which, on average, is smaller than the phase path in the averaged refractivity, and hence results in a negative bias in refractive index (Eshleman and Haugstad 1977). Through numerical simulations of radio occultations in a turbulent atmosphere, Gorbunov et al. (2015) demonstrated that this effect can result in a potentially significant negative bias of bending angles and refractivity derived from the Doppler shift, the main RO observable.

The fractional contribution of ducting-induced $N$ biases (from Fig. 8) to the total negative $N$ biases (from Fig. 7) is shown in Fig. 10. Note that the regions where the total $N$ bias is positive (as seen in Fig. 7) and where 


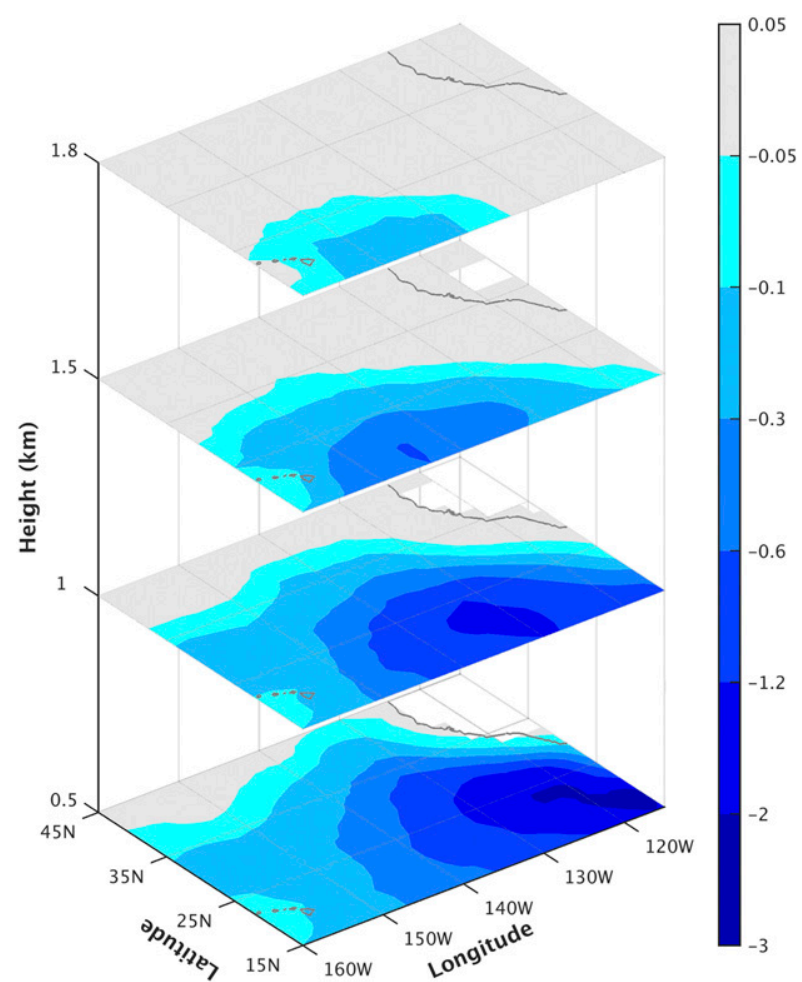

FIG. 8. Simulated ducting-induced $N$ bias $\left\langle\left(N_{\text {ERAI-simulated }}-\right.\right.$ $\left.\left.N_{\text {ERA }}\right) / N_{\text {ERA }}\right\rangle \times 100 \%$ at $0.5,1.0,1.5$, and $1.8 \mathrm{~km} \mathrm{MSL}$.

the fraction is greater than 1 are masked. The largest percentages are concentrated on the southeast corner of this domain where the ducting prevails (Fig. 1c), and the extreme values may exceed $50 \%$, with a maximum over $70 \%$ near the southern California coast. This indicates that ducting is the major cause of $N$ biases in the ducting prevailing region. For the full study region, ducting accounts for $\sim 25 \%$ of the total $N$ biases at both the $0.5-$ and $1.0-\mathrm{km}$ levels. However, the ducting-induced $N$ biases derived from ERA-I could be underestimated because of the relatively coarse ERA-I vertical resolution. Therefore, the $25 \%$ area-averaged $N$ biases due to ducting may be underestimated.

\section{Summary}

Using 8 years (2006-13) of COSMIC RO soundings and ERA-I reanalysis data, we have investigated the climatology and seasonality of the global ducting distributions and of the global COSMIC RO $\mathrm{N}$-bias distributions in comparison with ERA-I in the lower troposphere.

The systematically negative $N$ biases from RO soundings are confined to the lower troposphere over lower latitudes. The $N$ biases prevail below $\sim 2 \mathrm{~km}$, with a maximum magnitude of up to $\sim 6 \%$. Small

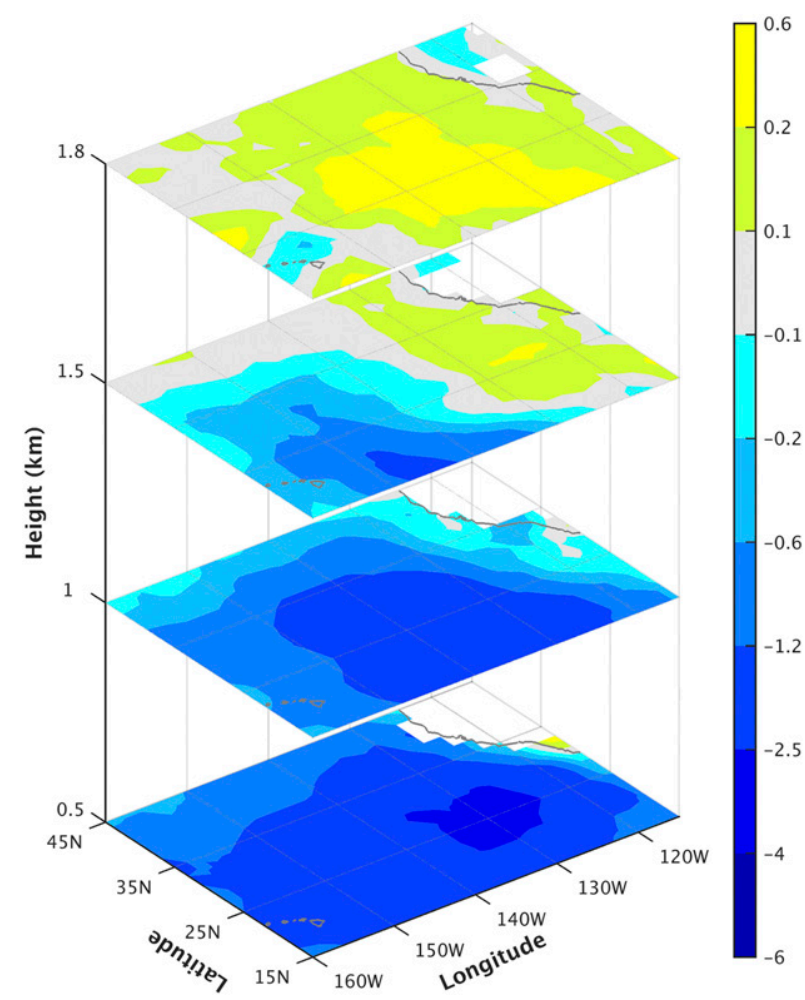

FIG. 9. Difference (\%) between observed COSMIC RO $N$ biases (Fig. 7) and ducting-induced $N$ biases in the ERA-I dataset (Fig. 8) at $0.5,1.0,1.5$, and $1.8 \mathrm{~km}$ MSL.

positive $N$ biases above $2 \mathrm{~km}$ over the tropics are also found. Over the oceans, large negative $N$ biases cluster over the subtropical oceans near the west coast of the continents. The magnitudes of $N$ biases are larger over oceans than over land, but their seasonality over land is larger than over oceans. The significant $N$ biases over land are mainly seen in regions of complex topography and appear to be caused by factors other than ducting.

The bending angles of ERA-I and MAGIC radiosondes are simulated in the northeast Pacific domain $\left(160^{\circ}-110^{\circ} \mathrm{W} ; 15^{\circ}-45^{\circ} \mathrm{N}\right)$. In this domain, systematically negative bending angle biases in COSMIC RO soundings with respect to collocated ERA-I data are found. Simulated bending angle profiles from MAGIC radiosondes confirm the existence and the magnitude of the RO bending angle biases. Significant negative bending angle biases are present below $\sim 2 \mathrm{~km}$, with the peak biases at $\sim 1 \mathrm{~km}$ above the surface, whereas the negative $N$ biases in this region peak at $\sim 0.5 \mathrm{~km}$. The locations of both the maximum biases in bending angles and refractivity tilt from northeast to southwest, following the increase of PBL height from less than $1 \mathrm{~km}$ offshore of southern California to about $1.8 \mathrm{~km}$ near Hawaii.

Moreover, the ducting-induced $N$ biases simulated from ERA-I data are calculated in the northeast Pacific 


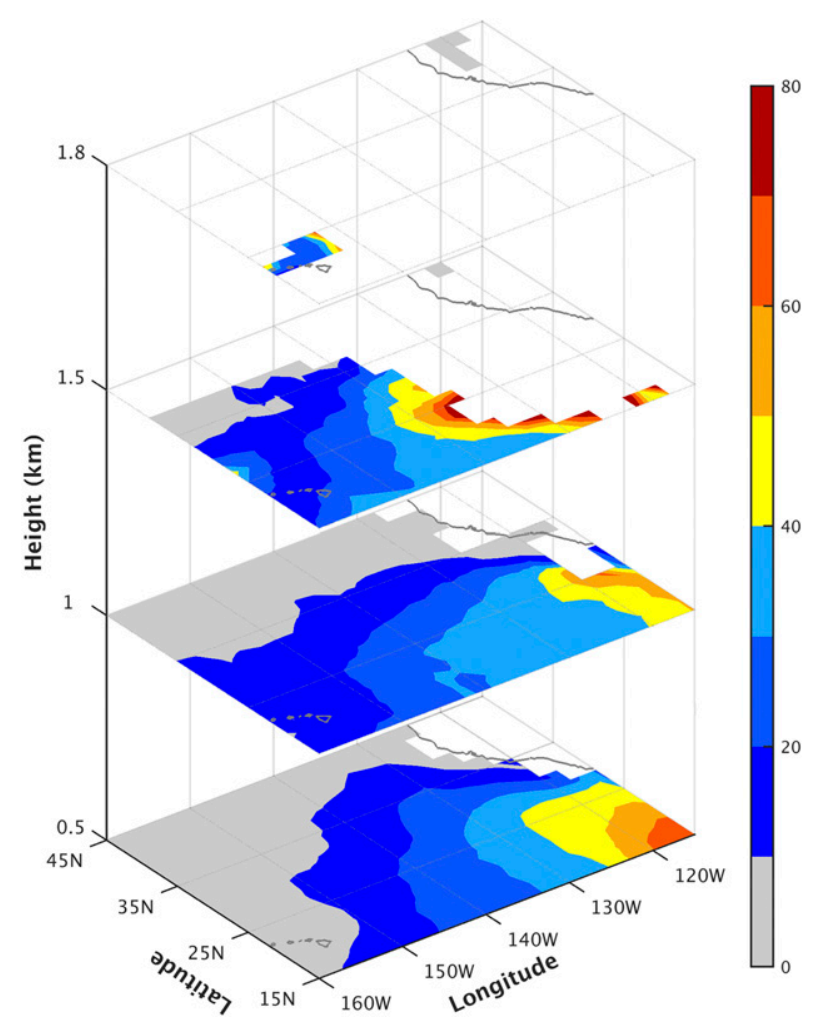

FIG. 10. The ratio (\%) of the magnitudes of the ducting-induced fractional $N$ biases (Fig. 8) to the observed COSMIC $N$ biases (Fig. 7) at 0.5, 1.0, 1.5 and $1.8 \mathrm{~km}$ MSL.

domain. Although with a smaller magnitude, they show a similar distribution pattern to the observed total COSMIC $N$ biases and confirm the importance of ducting to the observed negative RO biases. In regions with prevailing ducting, over $70 \%$ of $N$ biases can be attributed to ducting. Likely reasons for the non-ductinginduced negative refractivity and bending angle biases are retrieval errors in the complex lower moist troposphere under low-SNR conditions. Other reasons may be related to the Fermat principle in which radio waves take the path with the minimum integrated phase in an inhomogeneous medium. The underestimation of ductinginduced $N$ biases in the ERA-I analysis may also contribute to the apparent RO biases.

Acknowledgments. Authors X. Feng and F. Xie are supported by NASA Grants (NNX15AQ17G and NNH14ZDA001N-GNSS). The COSMIC RO soundings were provided by the Jet Propulsion Laboratory (JPL). Work performed by Author C. O. Ao was carried out at the JPL, California Institute of Technology, under a contract with NASA. Author R. Anthes was supported by NSF-NASA Grant AGS-1522830. The high-resolution ECMWF analysis data were acquired from ECMWF. The MAGIC field campaign data were collected by the U.S. Department of Energy Atmospheric Radiation Measurement (ARM) Program Climate Research Facility. We thank Sergey Sokolovskiy for his helpful comments on the causes of the RO biases. The support of Eric DeWeaver, Lucia S. Tsaoussi, and Jack Kaye is also greatly appreciated.

\section{REFERENCES}

Anthes, R. A., 2011: Exploring Earth's atmosphere with radio occultation: Contributions to weather, climate and space weather. Atmos. Meas. Tech., 4, 1077-1103, https://doi.org/ 10.5194/amt-4-1077-2011.

—, and Coauthors, 2008: The COSMIC/FORMOSAT-3 mission: Early results. Bull. Amer. Meteor. Soc., 89, 313-334, https:// doi.org/10.1175/BAMS-89-3-313.

Ao, C. O., 2007: Effect of ducting on radio occultation measurements: An assessment based on high-resolution radiosonde soundings. Radio Sci., 42, RS2008, https://doi.org/10.1029/ 2006RS003485.

— , T. K. Meehan, G. A. Hajj, A. J. Mannucci, and G. Beyerle, 2003: Lower troposphere refractivity bias in GPS occultation retrievals. J. Geophys. Res., 108, 4577, https://doi.org/10.1029/ 2002JD003216.

—- S. K. Chan, B. A. Iijima, J.-L. Li, A. J. Mannucci, J. Teixeira, B. Tian, and D. E. Waliser, 2008: Planetary boundary layer information from GPS radio occultation measurements. Proc. Workshop on Applications of GPS Radio Occultation Measurements, Reading, United Kingdom, ECMWF, 123-131, http://www.ecmwf.int/publications/library/ do/references/show?id $=88751$.

—, G. A. Hajj, T. K. Meehan, D. Dong, B. A. Iijima, A. J. Mannucci, and E. R. Kursinski, 2009: Rising and setting GPS occultations by use of open-loop tracking. J. Geophys. Res., 114, D04101, https://doi.org/10.1029/2008JD010483.

, D. E. Waliser, S. K. Chan, J.-L. Li, B. Tian, F. Xie, and A. J. Mannucci, 2012: Planetary boundary layer heights from GPS radio occultation refractivity and humidity profiles. J. Geophys. Res., 117, D16117, https://doi.org/10.1029/2012JD017598.

Basha, G., and M. V. Ratnam, 2009: Identification of atmospheric boundary layer height over a tropical station using highresolution radiosonde refractivity profiles: Comparison with GPS radio occultation measurements. J. Geophys. Res., 114, D16101, https://doi.org/10.1029/2008JD011692.

Beyerle, G., M. E. Gorbunov, and C. O. Ao, 2003: Simulation studies of GPS radio occultation measurements. Radio Sci., 38, 1084, https://doi.org/10.1029/2002RS002800.

_, T. Schmidt, J. Wickert, S. Heise, M. Rothacher, G. KonigLanglo, and K. B. Lauritsen, 2006: Observations and simulations of receiver-induced refractivity biases in GPS radio occultation. J. Geophys. Res., 111, D12101, https://doi.org/ 10.1029/2005JD006673.

Bonafoni, S., R. Biondi, H. Brenot, and R. Anthes, 2019: Radio occultation and ground-based GNSS products for observing, understanding and predicting extreme events: A review. Atmos. Res., 230, 104624, https://doi.org/10.1016/j.atmosres.2019.104624.

Born, M., and E. Wolf, 1964: Principles of Optics: Electromagnetic Theory of Propagation, Interference and Diffraction of Light. Pergamon Press, 856 pp.

Cucurull, L., and J. C. Derber, 2008: Operational implementation of COSMIC observations into NCEP's Global Data Assimilation 
System. Wea. Forecasting, 23, 702-711, https://doi.org/10.1175/ 2008WAF2007070.1.

Dee, D. P., and Coauthors, 2011: The ERA-Interim reanalysis: Configuration and performance of the data assimilation system. Quart. J. Roy. Meteor. Soc., 137, 553-597, https://doi.org/ 10.1002/qj.828.

Eshleman, V. R., and B. S. Haugstad, 1977: Lowest-order average effect of turbulence on atmospheric profiles derived from radio occultation. Astrophys. J., 214, 928-933, https://doi.org/ $10.1086 / 155325$.

Feng, D. D., and B. M. Herman, 1999: Remotely sensing the Earth's atmosphere using the global positioning system (GPS)-The GPS/MET data analysis. J. Atmos. Oceanic Technol., 16, 989-1002, https://doi.org/10.1175/1520-0426(1999) 016<0989:RSTESA $>2.0$. CO;2.

Fjeldbo, G., A. J. Kliore, and V. R. Eshleman, 1971: The neutral atmosphere of Venus as studied with the Mariner $\mathrm{V}$ radio occultation experiment. Astron. J., 76,123-140, https://doi.org/ 10.1086/111096.

Gorbunov, M. E., 2002a: Canonical transform method for processing radio occultation data in the lower troposphere. Radio Sci., 37, 1076, https://doi.org/10.1029/2000RS002592.

_ 2002b: Radio-holographic analysis of Microlab-1 radio occultation data in the lower troposphere. J. Geophys. Res., 107, 4156, https://doi.org/10.1029/2001JD000889.

—_, and A. S. Gurvich, 1998: Microlab-1 experiment: Multipath effects in the lower troposphere. J. Geophys. Res., 103, 13 819-13 826, https://doi.org/10.1029/98JD00806.

- H. H. Benzon, A. S. Jensen, M. S. Lohmann, and A. S. Nielsen, 2004: Comparative analysis of radio occultation processing approaches based on Fourier integral operators. Radio Sci., 39, RS6004, https://doi.org/10.1029/2003RS002916.

—_, V. V. Vorob'ev, and K. B. Lauritsen, 2015: Fluctuations of refractivity as a systematic error source in radio occultations. Radio Sci., 50, 656-669, https://doi.org/10.1002/ 2014RS005639.

Guo, P., Y.-H. Kuo, S. Sokolovskiy, and D. H. Lenschow, 2011: Estimating atmospheric boundary layer depth using COSMIC radio occultation data. J. Atmos. Sci., 68, 1703-1713, https:// doi.org/10.1175/2011JAS3612.1.

Healy, S. B., 2008: Forecast impact experiment with a constellation of GPS radio occultation receivers. Atmos. Sci. Lett., 9, 111-118, https://doi.org/10.1002/asl.169.

— CHAMP GPS radio occultation measurements. Quart. J. Roy. Meteor. Soc., 132, 605-623, https://doi.org/10.1256/qj.04.182.

Ho, S.-P., and Coauthors, 2009: Estimating the uncertainty of using GPS radio occultation data for climate monitoring: Intercomparison of CHAMP refractivity climate records from 2002 to 2006 from different data centers. J. Geophys. Res., 114, D23107, https://doi.org/10.1029/2009JD011969.

—, L. Peng, R. A. Anthes, Y.-H. Kuo, and H.-C. Lin, 2015: Marine boundary layer heights and their longitudinal, diurnal and inter-seasonal variability in the southeast Pacific using COSMIC, CALIOP, and radiosonde data. J. Climate, $\mathbf{2 8}$, 2856-2872, https://doi.org/10.1175/JCLI-D-14-00238.1.

— , and Coauthors, 2019: The COSMIC-FORMOSAT-3 radio occultation mission after 12 years: Accomplishments, remaining challenges, and potential impacts of COSMIC-2. Bull. Amer. Meteor. Soc., https://doi.org/10.1175/BAMS-D-18-0290.1, in press.

Jensen, A. S., M. S. Lohmann, H.-H. Benzon, and A. S. Nielsen, 2003: Full spectrum inversion of radio occultation signals. Radio Sci., 38, 1040, https://doi.org/10.1029/2002RS002763.
,,-- A. S. Nielsen, and H.-H. Benzon, 2004: Geometrical optics phase matching of radio occultation signals. Radio Sci., 39, RS3009, https://doi.org/10.1029/2003RS002899.

Kalmus, P., S. Wong, and J. Teixeira, 2015: The Pacific subtropical cloud transition: A MAGIC assessment of AIRS and ECMWF thermodynamic structure. IEEE Geosci. Remote Sens. Lett., 12, 1586-1590, https://doi.org/10.1109/ LGRS.2015.2413771.

Kuo, Y.-H., T.-K. Wee, S. Sokolovskiy, C. Rocken, W. Schreiner, D. Hunt, and R. A. Anthes, 2004: Inversion and error estimation of GPS radio occultation data. J. Meteor. Soc. Japan, 82, 507-531, https://doi.org/10.2151/jmsj.2004.507.

Kursinski, E. R., G. A. Hajj, J. T. Schofield, R. P. Linfield, and K. R. Hardy, 1997: Observing Earth's atmosphere with radio occultation measurements using the global positioning system. J. Geophys. Res., 102, 23 429-23 465, https://doi.org/10.1029/ 97JD01569.

Lopez, P., 2009: A 5-yr 40-km-resolution global climatology of superrefraction for ground-based weather radars. J. Appl. Meteor. Climatol., 48, 89-110, https://doi.org/10.1175/2008JAMC1961.1.

Luntama, J.-P., and Coauthors, 2008: Prospects of the EPS GRAS mission for operational atmospheric applications. Bull. Amer. Meteor. Soc., 89, 1863-1876, https://doi.org/ 10.1175/2008BAMS2399.1.

Poli, P., S. B. Healy, and D. P. Dee, 2010: Assimilation of global positioning system radio occultation data in the ECMWF ERA-Interim reanalysis. Quart. J. Roy. Meteor. Soc., 136, 1972-1990, https://doi.org/10.1002/qj.722.

Rocken, C. R., and Coauthors, 1997: Analysis and validation of GPS/MET data in the neutral atmosphere. J. Geophys. Res., 102, 29 849-29 866, https://doi.org/10.1029/97JD02400.

Smith, E. K., and S. Weintraub, 1953: The constants in the equation for atmospheric refractive index at radio frequencies. Proc. IRE, $\mathbf{4 1}$, 1035-1037, https://doi.org/10.1109/JRPROC.1953.274297.

Sokolovskiy, S., 2003: Effect of superrefraction on inversions of radio occultation signals in the lower troposphere. Radio Sci., 38, 1058, https://doi.org/10.1029/2002RS002728.

_ , Y.-H. Kuo, C. Rocken, W. S. Schreiner, D. Hunt, and R. A. Anthes, 2006: Monitoring the atmospheric boundary layer by GPS radio occultation signals recorded in the open-loop mode. Geophys. Res. Lett., 33, L12813, https://doi.org/10.1029/ 2006GL025955.

—, C. Rocken, D. H. Lenschow, Y.-H. Kuo, R. A. Anthes, W. S. Schreiner, and D. Hunt, 2007: Observing the moist troposphere with radio occultation signals from COSMIC. Geophys. Res. Lett., 34, L18802, https://doi.org/10.1029/2007GL030458.

,-- W. Schreiner, and D. Hunt, 2010: On the uncertainty of radio occultation inversions in the lower troposphere. J. Geophys. Res., 115, D22111, https://doi.org/10.1029/2010JD014058.

Thomas, M. E., 2006: Optical Propagation in Linear Media: Atmospheric Gases and Particles, Solid State Components, and Water. Oxford University Press, 584 pp.

Tsuda, T., N. Nishida, C. Rocken, and R. Ware, 2000: A global morphology of gravity wave activity in the stratosphere revealed by the GPS occultation data (GPS/MET). J. Geophys. Res., 105, 7257-7273, https://doi.org/10.1029/1999JD901005.

von Engeln, A., and J. Teixeira, 2004: A ducting climatology derived from the European Centre for Medium-Range Weather Forecasts global analysis fields. J. Geophys. Res., 109, D18104, https://doi.org/10.1029/2003JD004380.

Wang, K.-N., J. L. Garrison, U. Acikoz, J. S. Haase, B. J. Murphy, P. Muradyan, and T. Lulich, 2016: Open-loop tracking of rising and setting GPS radio-occultation signals from an airborne 
platform: Signal model and error analysis. IEEE Trans. Geosci. Remote Sens., 54, 3967-3984, https://doi.org/10.1109/ TGRS.2016.2532346.

—_, M. de la Torre Juarez, C. O. Ao, and F. Xie, 2017: Correcting negatively-biased refractivity below ducts in GNSS radio occultation: An optimal estimation approach towards improving planetary boundary layer (PBL) characterization. Atmos. Meas. Tech., 10, 4761-4776, https://doi.org/10.5194/amt-10-4761-2017.

Ware, R., and Coauthors, 1996: GPS sounding of the atmosphere from low Earth orbit: Preliminary results. Bull. Amer. Meteor. Soc., 77, 19-40, https://doi.org/10.1175/1520-0477(1996) $077<0019$ :GSOTAF $>2.0 . \mathrm{CO} ; 2$.

Wickert, J., and Coauthors, 2001: Atmosphere sounding by GPS radio occultation: First results from CHAMP. Geophys. Res. Lett., 28, 3263-3266, https://doi.org/10.1029/2001GL013117.

Xie, F., 2006: Development of a GPS occultation retrieval method for characterizing the marine boundary layer in the presence of super-refraction. Ph.D. dissertation, University of Arizona, 134 pp.

— S. Syndergaard, E. R. Kursinski, and B. M. Herman, 2006: An approach for retrieving marine boundary layer refractivity from GPS radio occultation data in the presence of superrefraction. J. Atmos. Oceanic Technol., 23, 1629-1644, https:// doi.org/10.1175/JTECH1996.1.

_- D. L. Wu, C. O. Ao, E. R. Kursinski, A. Mannucci, and S. Syndergaard, 2010: Super-refraction effects on GPS radio occultation refractivity in marine boundary layers. Geophys. Res. Lett., 37, L11805, https://doi.org/10.1029/ 2010 GL043299.

,,-- A. J. Mannucci, and E. R. Kursinski, 2012: Advances and limitations of atmospheric boundary layer observations with GPS occultation over southeast Pacific Ocean. Atmos. Chem. Phys., 12, 903-918, https://doi.org/10.5194/acp12-903-2012.

Yu, X., F. Xie, and C. O. Ao, 2018: Evaluating the lowertropospheric COSMIC GPS radio occultation sounding quality over the Arctic. Atmos. Meas. Tech., 11, 2051-2066, https:// doi.org/10.5194/amt-11-2051-2018.

Zeng, Z., S. Sokolovskiy, W. S. Schreiner, and D. Hunt, 2019: Representation of vertical structures by radio occultation observations in the upper troposphere and lower stratosphere: Comparison to high-resolution radiosonde profiles. J. Atmos. Oceanic Technol., 36, 655-670, https://doi.org/10.1175/JTECHD-18-0105.1.

Zheng, Y., and D. Rosenfeld, 2015: Linear relation between convective cloud base height and updrafts and application to satellite retrievals. Geophys. Res. Lett., 42, 6485-6491, https:// doi.org/10.1002/2015GL064809.

Zhou, X., P. Kollias, and E. Lewis, 2015: Clouds, precipitation and marine boundary layer structure during MAGIC. J. Climate, 28, 2420-2442, https://doi.org/10.1175/JCLI-D14-00320.1. 